\title{
3D FEM Simulation of Water Vapor Jet Assisted Metal Cutting
}

\author{
$\mathrm{Yu} \mathrm{Su}{ }^{*}$
}

College of Mechanical Engineering, Jiangsu University of Science and Technology, Zhenjiang 212003, P.R. China

\begin{abstract}
Water vapor jet assisted metal cutting is a pollution-free green cutting technique. This paper has developed a three-dimensional finite element model of water vapor jet assisted cutting in order to understand the influence of its cooling and lubricating effect on cutting process. The cooling effect of water vapor jet is modeled with a convective heat transfer coefficient. A window with the temperature and the heat transfer coefficient of water vapor jet, which can move at the same speed as the tool, has been defined on the tool face so as to continuously simulate cooling process of the cutting zone under water vapor jet condition. Friction contact between tool and chip is modeled by a constant shear model. The shear friction factor with different values has been set to study the influence of lubricating effect of water vapor jet. Simulation results show that compared with its cooling effect, the lubricating effect of water vapor jet is more effective to reduce cutting force and tool temperature. A further improvement in the lubricating effect of water vapor jet also results in an obvious reduction in cutting force and tool temperature. The findings obtained in this study may provide helpful information for developing water vapor jet assisted cutting process.
\end{abstract}

Keywords: Cooling and lubrication, Finite element method, Metal cutting, Water vapor jet.

\section{INTRODUCTION}

In metal cutting, heat generation and friction at the cutting zone usually limit machining performance. Using cutting fluids is a traditional approach to improve the tribological characteristics of cutting process and dissipate the generated heat. Unfortunately, application of conventional cutting fluids has several adverse effects such as environmental pollution, high cost, and hazards to employee health [1-3]. All the factors have promoted researchers to search for some alternatives to reduce the usage of cutting fluids.

In the 1990s, Podgorkov et al. [4] and Godlevski et al. [5] proposed a new and pollution-free green cutting technique with water vapor as coolant and lubricant in cutting process. Results showed that water vapor can ensure more uniform cooling and increase the tool life of carbide tools 2-2.5 times in turning and 2-4 times in milling carbon and stainless steels. In recent years, Liu et al. [6-8] developed a water vapor generator and carried out the turning experiments of ANSI 1045 steel and ANSI 304 stainless steel with cemented carbide tools under the conditions of water vapor, compressed air, oil water emulsion, oxygen, carbon dioxide gas and dry cutting, respectively. They found that compared with compressed air, oil water emulsion, oxygen and carbon dioxide gas, application of water vapor reduced cutting force, friction coefficient, cutting temperature and tool wear more effectively. Liu et al. [9] also studied the influence of water

*Address correspondence to this author at the College of Mechanical Engineering, Jiangsu University of Science and Technology, Zhenjiang 212003, P.R. China; Tel: +86-511-84401442; Fax: +86-511-84401142; E-mail: suyuliu@sohu.com vapor on the machining performance of $\mathrm{Ni}$ based super alloy and Ti-6Al-4V, and reported that the cutting force with water vapor was lower than that with dry cutting and wet machining for all machining conditions. The tool life extended by two-six times than dry cutting, about two-four times than oil water emulsion during machining Ti-6Al-4V with application of water vapor direct into the cutting zone. Ren et al. [10] investigated the effect of saturated vapor pressure, nozzle diameter, and cooling distance on cutting force and chip thickness in the water vapor jet assisted cutting of C45 steel. The results showed that increase of saturated vapor pressure, and decrease of cooling distance and nozzle diameter caused the reduction of cutting force and chip thickness. Wu et al. [11] performed the comparative drilling experiments for various difficult-tomachine materials under the conditions of oil water emulsion, water vapor, and dry drilling. It was reported that the flank wear with water vapor reduced by $45-80 \%$ and $10-$ $15 \%$ in comparison with dry drilling and oil water emulsion, respectively. The above-mentioned experimental studies indicate that water vapor assisted metal cutting may improve the machining performance of many materials significantly due to its superior cooling/lubricating effect. However, it is difficult to determine by experiment how much improvement in machining performance can be brought about by the cooling and lubricating effect of water vapor jet, respectively.

Finite element method is an efficient way to model cutting process. Using FEM cutting simulation can get the values of process variables that are not measurable or very difficult to measure by experiment. The information provides a better understanding of metal cutting mechanics. Some researchers have adopted FEM to study the effect of green cutting techniques on machining performance. For instance, 
Shet et al. [12] developed a 2D finite element model of highpressure water jet assisted metal cutting, in which the water jet was injected directly at the tool-chip interface through a small hole on the rake face, and studied the effect of water jet hole position and pressure in machining of AISI 4340 steel. It was confirmed that when a high-pressure jet is injected into the tool-chip interface through the tool, substantial reductions in the interface contact pressure and shear stress, the tool-chip contact length, the temperature in the cutting zone, and the residual stresses in the finished workpiece could be observed. However, as yet no model is known to simulate water vapor jet assisted cutting process. Therefore, the purpose of the present study is to build a three-dimensional finite element model of water vapor jet assisted cutting and investigate the influence of cooling and lubricating effect of water vapor jet on machining performance of AISI 1045 steel.

\section{FINITE ELEMENT MODELING DETAILS}

The commercial FEA software Deform 3D is used to simulate the cylindrical turning process of AISI 1045 steel under water vapor jet condition. The workpiece is represented by a curved model with $50 \mathrm{~mm}$ diameter. The workpiece is a rigid-plastic body, initially meshed with 15000 elements, and the tool is a rigid body meshed with 10000 elements. A fine mesh density is defined at the tool tip and at the cutting zone in order to obtain fine process output. Fig. (1) shows the general arrangement and mesh configuration of the developed FEM model of cylindrical turning. The workpiece is fixed and the tool moves at the specified cutting speed. A high value of heat transfer coefficient at the tool-chip interface is set to allow rapid temperature rise in the tool so that thermal steady-state can be achieved in the numerical simulation.

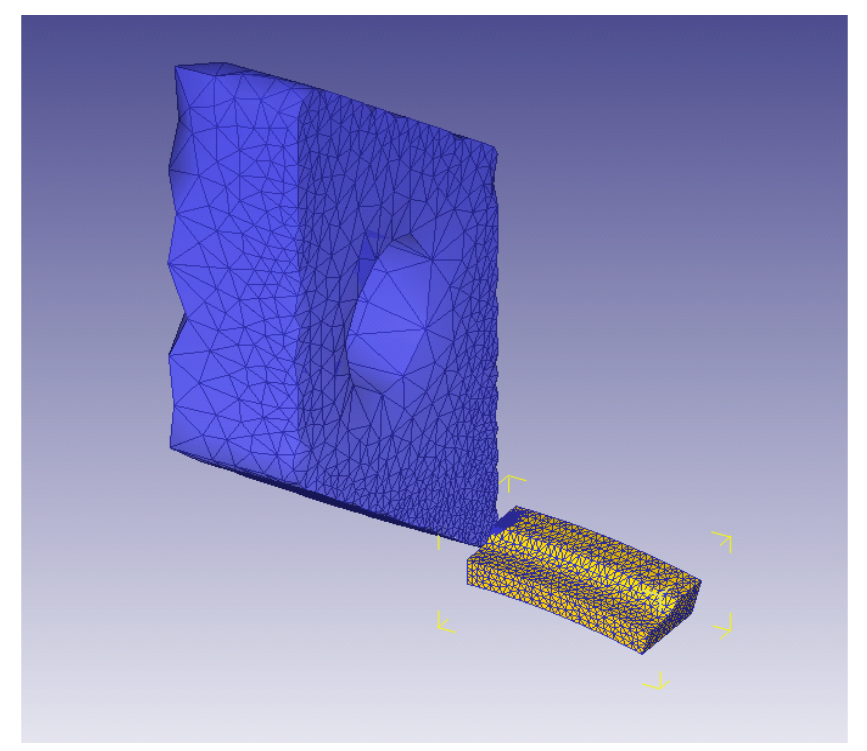

Fig. (1). General arrangement and mesh configuration used in the cylindrical turning simulation.

\subsection{Workpiece and Tool Specifications}

The AISI 1045 steel with its wide range of application has been chosen for studying the effect of water vapor jet assisted cutting. To model the behavior of AISI 1045 steel, a classical Johnson-Cook constitutive law is employed, which can be represented by the following equation [13].

$$
\sigma=\left(A+B \varepsilon^{n}\right)\left(1+C \ln \frac{\dot{\varepsilon}}{\dot{\varepsilon}_{0}}\right)\left[1-\left(\frac{T-T_{r}}{T_{m}-T_{r}}\right)^{m}\right],
$$

where $\varepsilon$ is the plastic strain, $\dot{\varepsilon}$ is the strain rate $\left(\mathrm{s}^{-1}\right), \dot{\varepsilon}_{0}$ is the reference plastic strain rate $\left(\mathrm{s}^{-1}\right), T$ is the temperature of workpiece $\left({ }^{\circ} \mathrm{C}\right), T_{m}$ is the melting temperature of the workpiece $\left({ }^{\circ} \mathrm{C}\right), T_{r}$ is the room temperature $\left({ }^{\circ} \mathrm{C}\right)$. Coefficient $A$ is the yield strength (MPa), $B$ is the hardening modulus (MPa), $C$ is the strain rate sensitivity coefficient, $n$ is the hardening coefficient and $m$ is the thermal softening coefficient. The material coefficients can be obtained by using Split-Hopkinson pressure bar (SHPB) tests performed under various strain rates and temperatures. Based on the work of Jaspers et al. [14], AISI 1045 material constants for Johnson-Cook constitutive law are given in Table $\mathbf{1}$.

Table 1. Johnson-Cook workpiece material constants for AISI 1045.

\begin{tabular}{|c|c|c|c|c|}
\hline $\boldsymbol{A}$ (MPa) & $\boldsymbol{B}$ (MPa) & $\boldsymbol{C}$ & $\boldsymbol{n}$ & $\boldsymbol{m}$ \\
\hline \hline 553.1 & 600.8 & 0.0134 & 0.234 & 1 \\
\hline
\end{tabular}

Cemented carbide is selected as tool material in the developed FEM model. The mechanical and physical properties of the cemented carbide and AISI 1045 are listed in Table 2.

Table 2. The mechanical and physical properties of workpiece and tool material.

\begin{tabular}{|c|c|c|}
\hline Parameters & $\begin{array}{c}\text { Workpiece } \\
\text { (AISI 1045) }\end{array}$ & $\begin{array}{c}\text { Cutting Tool } \\
\text { (Cemented Carbide) }\end{array}$ \\
\hline \hline Young's modulus (MPa) & 200000 & 650279 \\
\hline Poisson's ratio & 0.3 & 0.25 \\
\hline Thermal conductivity (W/m K) & 55 & 58.9888 \\
\hline Heat capacity $\left(\mathrm{N} / \mathrm{mm}^{2} /{ }^{\circ} \mathrm{C}\right)$ & 3.6972 & 3.042 \\
\hline
\end{tabular}

\subsection{Modeling of Cooling Effect}

In the water vapor jet assisted cutting, water vapor is jetted to the cutting zone which dissipates the heat by means of heat convection. In this research, the cooling effect provided by water vapor jet is modeled with a convective heat transfer coefficient, $h$, as given below

$q_{\mathrm{c}}=h\left(T-T_{0}\right)$,

where $q_{\mathrm{c}}$ is the density of heat flow rate, $T$ is the surface temperature of the tool or workpiece, and $T_{0}$ is the temperature of water vapor jet $\left(100^{\circ} \mathrm{C}\right)$. The cooling effect of water vapor jet belongs to forced convection heat transfer. According to the work of Yang et al. [15], the heat transfer coefficient for water vapor jet is assumed to be 100 $\left(\mathrm{W} / \mathrm{Km}^{2}\right)$. As shown in Fig. (2), a window with the temperature and the heat transfer coefficient of water vapor 
jet, which can move at the same speed as the tool, has been defined on the tool face so as to continuously simulate cooling process of the cutting zone under water vapor jet condition.

\subsection{Friction Modeling}

In the present simulation, friction contact between tool and chip is modeled by a constant shear model in which a shear friction factor, $f$, is used to represent the friction at entire tool-chip interface. The shear friction factor is set equal to 0.6 for dry cutting and water vapor jet when its cooling effect is only considered. As water vapor accesses the cutting zone with high speed jet flow, it fills up capillaries in cutting zone and forms boundary lubricating layer, thus reducing the friction at the cutting interface. In order to study the influence of lubricating effect of water vapor jet on the machining performance, the shear friction factor is also assumed to be 0.5 and 0.4 for water vapor jet, respectively.

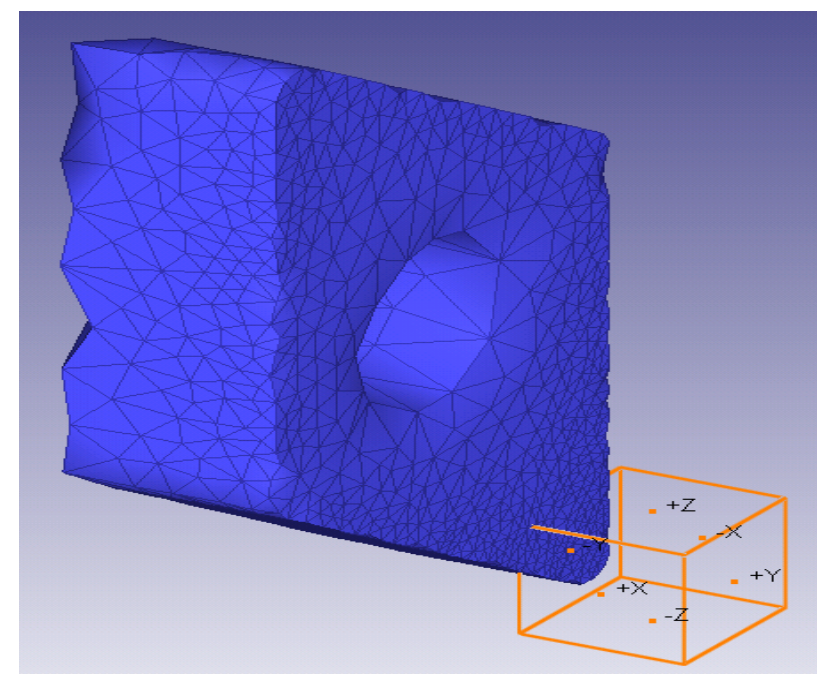

Fig. (2). The heat transfer window used to simulate cooling effect of water vapor jet.

\subsection{Simulation Parameters}

During the simulation, the cutting speed is kept at 104.67 $\mathrm{m} / \mathrm{min}$, and feed rate as well as depth of cut are set equal to $0.3 \mathrm{~mm} / \mathrm{r}$ and $0.5 \mathrm{~mm}$, respectively. The simulated cutting environments include dry cutting and water vapor jet. Simulations are run for $0.00375 \mathrm{~s}$ cutting time.

\section{RESULTS AND DISCUSSION}

\subsection{Influence of Water Vapor Jet on Cutting Force}

Fig. (3) shows a comparison of predicted main cutting force for various cooling/lubrication conditions. As shown in Fig. (3), there is an obvious reduction in main cutting force for water vapor as compared with dry cutting. The cooling and lubricating effect of water vapor may reduce cutting force by means of reducing plasticity of workpiece and friction at tool-chip interface, respectively. Compared with dry cutting, the reduction of cutting force under water vapor $(f=0.6)$ condition is due to the cooling effect. And compared with water vapor $(f=0.6)$, the reduction of cutting force under water vapor $(f=0.5)$ condition is due to the lubricating effect of water vapor. It can be seen from Fig. (3) that the percentage reduction in main cutting force resulting from the cooling and lubricating effect of water vapor is $3.4 \%$ and $9.6 \%$, respectively. This means that the lubricating effect provided by water vapor is more effective than its cooling effect in terms of reduction in cutting force. Besides, for water vapor jet, a $10 \%$ reduction in main cutting force can also be observed when further reducing its shear friction factor from 0.5 to 0.4 . This indicates that improving the lubricating effect of water vapor still resulted in a considerable reduction in cutting force.

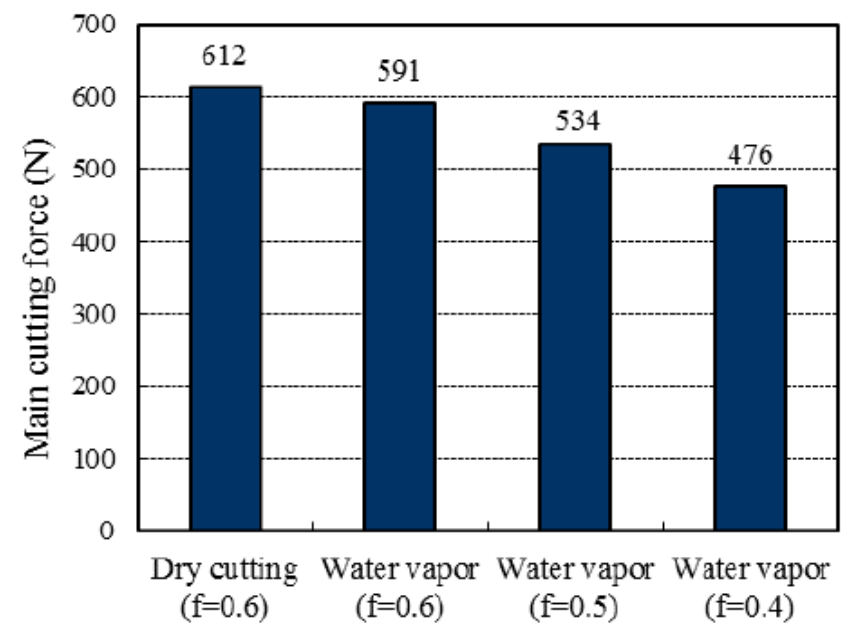

Cooling/lubrication conditions

Fig. (3). Comparison of the predicted main cutting force for various cooling/lubrication conditions.

\subsection{Influence of Water Vapor Jet on Cutting Temperature}

Cutting temperature is a key factor which affects tool wear and machined surface quality during the machining. Fig. (4) shows the predicted steady-state tool temperature distributions for various cooling/lubrication conditions. The maximum temperature is also indicated in each distribution. As shown in Fig. (4), the tool temperature distribution is greatly influenced by the variation of cooling/lubrication conditions. Compared to dry cutting, a global decrease of tool temperature can be seen with application of water vapor jet. In the present simulation, the maximum tool temperature, average rake temperature, and average flank temperature are used to evaluate the influence of water vapor on tool temperature. A series of points are defined on the rake face and flank face, respectively, and their steady-state temperature values are extracted and averaged as average rake and flank temperature, respectively, as illustrated in Fig. (5). In order to ensure the effectiveness of evaluation, the number and position of the defined points on the rake and flank face are the same for dry cutting and water vapor jet. The predicted tool temperature values for dry cutting and water vapor jet are given in Table 3. It can be seen from 
(a) Dry cutting $(f=0.6)$

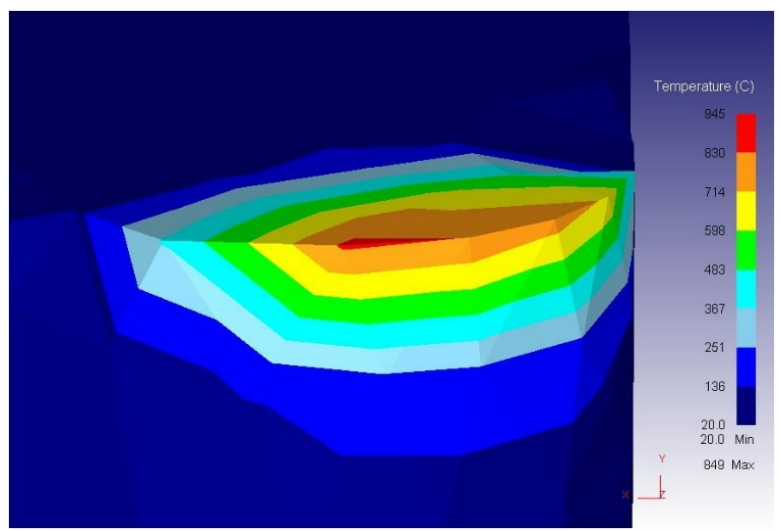

(b) Water vapor jet $(f=0.6)$

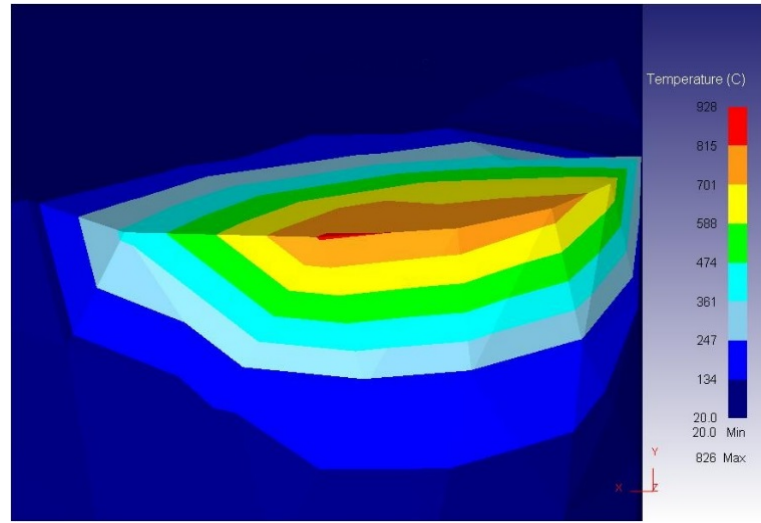

(c) Water vapor jet $(f=0.5)$

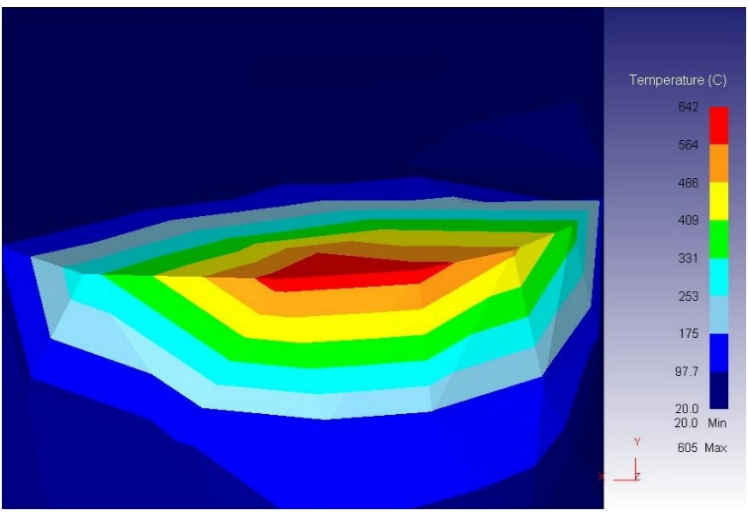

(d) Water vapor jet $(f=0.4)$

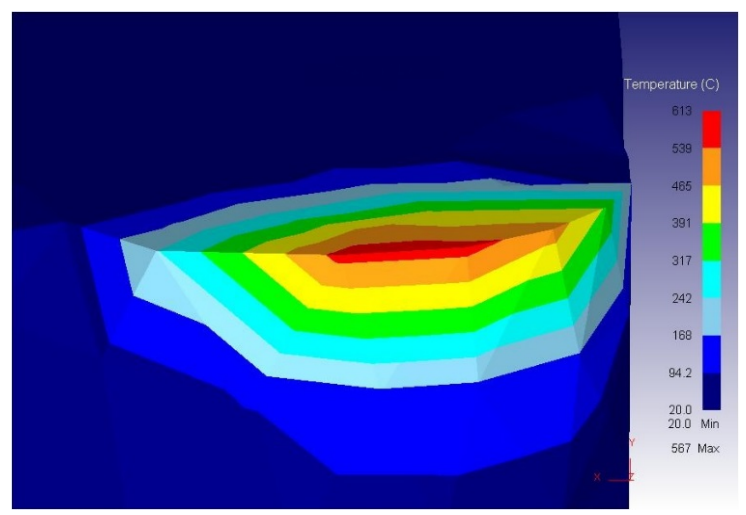

Fig. (4). Predicted tool temperature distribution under different cooling/lubrication conditions. (a) Rake face

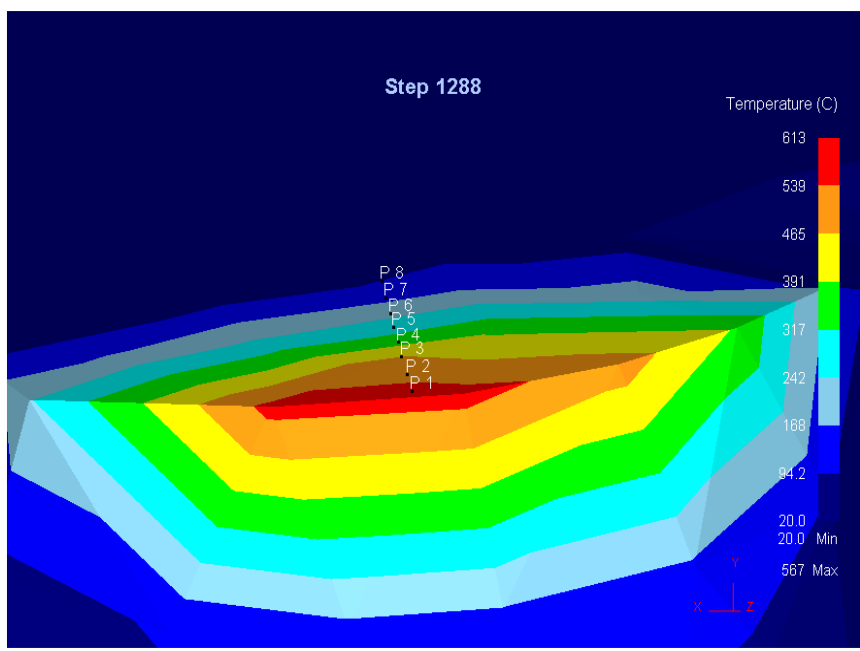

(b) Flank face

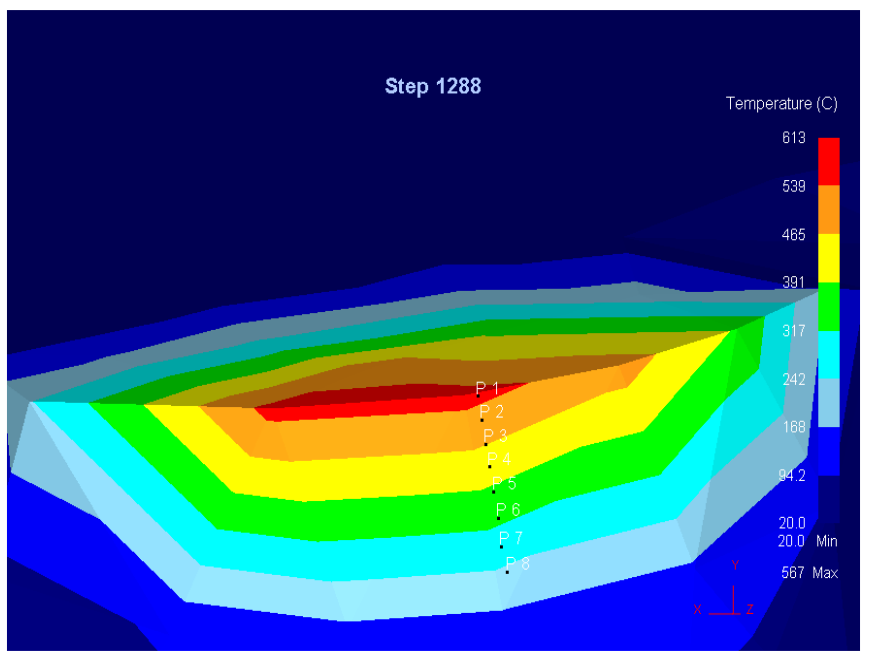

Fig. (5). Some points defined on rake and flank face for calculating the tool temperature.

Table 3 that the reduction of maximum tool temperature, average rake temperature, and average flank temperature by the cooling effect of water vapor is much smaller than that by the lubricating effect provided by water vapor. And a further obvious reduction of tool temperature is brought about by the improvement of lubrication effect provided by water vapor. Effective lubrication between the chip and cutting tool not only results in the generation of lower amounts of heat due to the lower friction, but also reduces the heat generation due to plastic deformation, thus reducing the tool temperature effectively. The detailed percentage reduction of tool temperature is listed in Tables 4-6.

Simulation results illustrate that in machining of AISI 1045 steel with cemented carbide, the effect of water vapor jet is more lubricating rather than cooling. As mentioned by Liu et al. [6-8], better lubricating action can be obtained with water vapor as coolant and lubricant because of its excellent penetration performance. Water vapor impinges the tool-chip interface at high speed and quickly fills up the capillaries, thus reducing the contact friction, cutting force and cutting temperature. The state of water vapor jet flow, like 
Table 3. The Predicted Tool Temperature Values for Dry Cutting and Water Vapor Jet

\begin{tabular}{|c|c|c|c|}
\hline Cooling/Lubrication Conditions & Maximum Tool Temperature $\left({ }^{\circ} \mathbf{C}\right)$ & Average Rake Temperature $\left({ }^{\circ} \mathbf{C}\right)$ & Average Flank Temperature $\left({ }^{\circ} \mathbf{C}\right)$ \\
\hline \hline Dry cutting $(f=0.6)$ & 849 & 544 & 574 \\
\hline Water vapor $(f=0.6)$ & 826 & 529 & 557 \\
\hline Water vapor $(f=0.5)$ & 605 & 361 & 424 \\
\hline Water vapor $(f=0.4)$ & 567 & 324 & 391 \\
\hline
\end{tabular}

temperature and velocity, has direct influence on its penetration performance and its cooling/lubricating effect. So it is necessary to establish a reliable relationship between them. Thus the temperature and velocity of water vapor jet can be properly selected in order to apply this green cutting technique effectively.

Table 4. Percentage Reduction in Tool Temperature for Water Vapor $(f=0.6)$ Relative to Dry Cutting $(f=0.6)$

\begin{tabular}{|llll|}
\hline & $\begin{array}{l}\text { Percentage } \\
\text { reduction in } \\
\text { maximum tool } \\
\text { temperature }\end{array}$ & $\begin{array}{l}\text { Percentage } \\
\text { reduction in } \\
\text { average rake } \\
\text { temperature }\end{array}$ & $\begin{array}{l}\text { Percentage } \\
\text { reduction in } \\
\text { average flank } \\
\text { temperature }\end{array}$ \\
\cline { 2 - 5 } & $\begin{array}{l}\text { Compared with } \\
\text { dry cutting } \\
(f=0.6)\end{array}$ & $\begin{array}{l}\text { Compared } \\
\text { with dry } \\
\text { cutting } \\
(f=0.6)\end{array}$ & $\begin{array}{l}\text { Compared } \\
\text { with dry } \\
\text { cutting } \\
(f=0.6)\end{array}$ \\
\hline $\begin{array}{l}\text { Water vapor } \\
(f=0.6)\end{array}$ & 2.7 & 2.9 & 2.9 \\
\hline
\end{tabular}

Table 5. Percentage Reduction in Tool Temperature for Water Vapor $(f=0.5)$ Relative to Water Vapor $(f=0.6)$

\begin{tabular}{|c|c|c|c|}
\hline \multirow{2}{*}{$\begin{array}{l}\text { Cooling/ } \\
\text { lubrication } \\
\text { conditions }\end{array}$} & $\begin{array}{l}\text { Percentage } \\
\text { reduction in } \\
\text { maximum tool } \\
\text { temperature }\end{array}$ & $\begin{array}{l}\text { Percentage } \\
\text { reduction in } \\
\text { average rake } \\
\text { temperature }\end{array}$ & $\begin{array}{l}\text { Percentage } \\
\text { reduction in } \\
\text { average flank } \\
\text { temperature }\end{array}$ \\
\hline & $\begin{array}{l}\text { Compared with } \\
\text { water vapor }(f=0.6)\end{array}$ & $\begin{array}{l}\text { Compared with } \\
\text { water vapor } \\
(f=0.6)\end{array}$ & $\begin{array}{l}\text { Compared } \\
\text { with water } \\
\text { vapor }(f=0.6)\end{array}$ \\
\hline $\begin{array}{l}\text { Water } \\
\text { vapor } \\
(f=0.5)\end{array}$ & 26.8 & 31.7 & 23.9 \\
\hline
\end{tabular}

Table 6. Percentage Reduction in Tool Temperature for Water Vapor $(f=0.4)$ Relative to Water Vapor $(f=0.5)$

\begin{tabular}{|llll|}
\hline Cooling/lubricat & $\begin{array}{l}\text { Percentage } \\
\text { reduction in } \\
\text { maximum tool } \\
\text { temperature }\end{array}$ & $\begin{array}{l}\text { Percentage } \\
\text { reduction in } \\
\text { average rake } \\
\text { temperature }\end{array}$ & $\begin{array}{l}\text { Percentage } \\
\text { reduction in } \\
\text { average flank } \\
\text { temperature }\end{array}$ \\
\cline { 2 - 4 } & $\begin{array}{l}\text { Compared with } \\
\text { water vapor } \\
(f=0.5)\end{array}$ & $\begin{array}{l}\text { Compared } \\
\text { with water } \\
\text { vapor }(f=0.5)\end{array}$ & $\begin{array}{l}\text { Compared with } \\
\text { water vapor } \\
(f=0.5)\end{array}$ \\
\hline $\begin{array}{l}\text { Water vapor } \\
(f=0.4)\end{array}$ & 6.3 & 10.3 & 7.6 \\
\hline
\end{tabular}

\section{CONCLUSION}

In this study, a 3D numerical model of water vapor jet assisted metal cutting has been presented. The effect of water vapor jet on the machining performance of AISI 1045 steel is analyzed by using FEM cutting simulation. Results from the simulations show that improved machinability with water vapor jet is mainly attributed to its lubricating effect rather than its cooling effect. Optimization of the velocity and temperature of water vapor jet is very important in order to get its distinguished penetration performance and lubricating effect. The trends revealed by the simulations provide a basis for planning machining process with the use of water vapor jet.

\section{CONFLICT OF INTEREST}

The author confirms that this article content has no conflict of interest.

\section{ACKNOWLEDGEMENTS}

The author wishes to acknowledge the financial support for this research by National Natural Science Foundation of China under contract no. 51205177, Natural Science Foundation of Jiangsu Province under contract no. BK2012277, Natural Science Program for Basic Research of Jiangsu Province under contract no. 08KJB460002, Qing Lan Project, and Research Fund of DML-HYIT (HGDML0901).

\section{REFERENCES}

[1] J.W. Sutherland, V.N. Kulur, and N.C. King, "An experimental investigation of air quality in wet and dry turning", Annals of the CIRP, vol. 49, pp. 61-64, 2000.

[2] F. Klocke, "Dry cutting", Annals of the CIRP, vol. 46, pp. 519-526, 1997.

[3] P.S. Sreejith, and B.K.A. Ngoi, "Dry machining: Machining of the future”, Journal of Materials Processing Technology, vol. 101, pp. 287-291, 2000.

[4] V.V. Podgorkov, "Method of cutting in application," Patent of USSR \#1549721 MCI B23Q, 1992 (in Russia).

[5] V.A. Godlevski, "Water steam lubrication during machining", Tribologia, vol. 162, pp. 11, 1998

[6] J.Y. Liu, R.D. Han, and Y.F. Sun, "Research on experiments and action mechanism with water vapor as coolant and lubricant in Green cutting", International Journal of Machine Tools \& Manufacture, vol. 45, pp. 687-694, 2005.

[7] J.Y. Liu, R.D. Han, L. Zhang, "Study on lubricating characteristic and tool wear with water vapor as coolant and lubricant in green cutting", Wear, vol. 262, 442-452, 2007.

[8] J.Y. Liu, H.P. Liu, R.D. Han, "The study on lubrication action with water vapor as coolant and lubricant in cutting ANSI 304 stainless steel", International Journal of Machine Tools \& Manufacture, vol. 50, pp. 260-269, 2010.

[9] J.Y. Liu, R.D. Han, and Y. Wang, "Research on difficult-cutmaterial in cutting with application of water vapor as coolant and 
lubricant", Industrial Lubrication and Tribology, vol. 62, pp. 251$262,2010$.

[10] J.J. Ren, J. L. Ren, Y. Wang, "Research on the Green Cutting Process with Water Vapor for the Cooling Lubricant", Advanced Materials Research, vol. 356-360, pp. 2241-2245, 2012.

[11] J. Wu and R.D. Han, "Wear of Uncoated HSS Tools in Drilling Difficult-to-Machine Materials with Water Vapor as Coolant and Lubricant", Advanced Materials Research, vol. 189-193, pp. 32133217, 2011.

[12] C. Shet, X.M. Deng, and A.E Bayoumi, "Finite element simulation of high-pressure water-jet assisted metal cutting", International Journal of Mechanical Sciences, vol. 45, pp. 1201-1228, 2003.
[13] G.R. Johnson and W.H. Cook, "A constitutive model and data for metals subjected to large strains, high strain rates and high temperature", in the 7th international symposium on ballistics, 1983, pp. 541-547.

[14] S.P.F.G. Jaspers and J.H. Dauzenburg, "Material behavior in conditions similar to metal cutting: flow stress in the primary shear zone", Journal of Materials Processing Technology, vol. 122, pp.322-330, 2002.

[15] S.M. Yang and W.Q. Tao, Heat transfer. Beijing: Higher Education Press, 1998.

Received: January 17, 2014

(C) Yu Su; Licensee Bentham Open.

This is an open access article licensed under the terms of the Creative Commons Attribution Non-Commercial License (http://creativecommons.org/licenses/ by-nc/4.0/) which permits unrestricted, non-commercial use, distribution and reproduction in any medium, provided the work is properly cited. 